Journal of

Applied

Linguistics

and

Professional

Practice
JALPP (PRINT) ISSN 2040-3658

JALPP (ONLINE) ISSN 2040-3666

Forum Discussion

\title{
Practising applied linguistics and the change agenda
}

\author{
Srikant Sarangi, Tarja Nikula and Anne Pitkänen-Huhta
}

\section{Preamble}

This Forum Discussion is in the form of a 'conversation', but unlike ordinary conversation it has continually evolved over a period of more than a year, both in face-toface meetings (being recorded and selected parts transcribed) and in a remote format via email correspondence. This written version has been subjected to heavy editing in order to remain focused and coherent.

Early on we agreed to target this conversational piece for the readers of the Journal of Applied Linguistics and Professional Practice (JALPP), as a rejoinder to other relevant conversations since the launch of the journal as the Journal of Applied Linguistics (JAL) in 2004. There are three main drivers for the discussion that follows.

(1) When JAL was launched in 2004, Chris Candlin and Srikant Sarangi as coeditors wrote a three-part sequel (Candlin and Sarangi 2004a, 2004b; Sarangi and Candlin 2004), respecifying what gap JAL was to fill and what kinds of applied linguistic research would make their way to the journal. These editorials were complemented with three high-profile special features in the form of conversations between Chris Brumfit and David Crystal (2004), Shirley Brice Heath and Claire Kramsch (2004) and Michael Halliday and Anne Burns (2006). Fifteen years have gone by, and so it is a good occasion to take stock and revisit some of the issues raised for the journal readership, although since 2010 JAL has transformed into JALPP, with a more streamlined agenda for the future (Sarangi and Candlin 2010).

(2) Beginning 2016, the Academy of Finland in collaboration with local universities initiated what has come to be known as profiling of research areas. At University

\footnotetext{
$\overline{\text { Contact author }}$

Srikant Sarangi: Department of Communication \& Psychology, Aalborg University, Rendsburggade 14, 9000 Aalborg, Denmark.

Email: sarangi@hum.aau.dk
} 
of Jyväskylä (JYU) applied language studies was identified as an area to be profiled, bearing the label 'Research Collegium for Language in Changing Society' (RECLAS). This profiling initiative, which formally ended in 2020, provided a platform for the Forum Discussion, while actively connecting to the JAL conversations fifteen years ago. Historically, since the early 1970s, JYU has had an unparalleled track record in establishing and nourishing applied linguistics (AL) as a specialised field of study, complemented by the annual International Summer School series since 1977, the inauguration of the Centre for Applied Language Studies (CALS) in 1996 and the launch of Apples - Journal of Applied Language Studies in 2001. It is this formidable track record in AL that must have been a catalyst in the Academy's decision to fund the profiling exercise in this area. More generally, AL as a field of study has been thriving in the Finnish context - 2020 marks the fiftieth anniversary of the Association of Finnish Applied Linguistics (AFinLA).

(3) The Forum Discussion involves three participants: Tarja Nikula [TN] and Anne Pitkänen-Huhta [AP] as the co-ordinators of RECLAS, and Srikant Sarangi [SS] as the external advisor in the role of Visiting Professor in the period 2017-2020. In addition to their affiliations with RECLAS, they represent different domains of scholarship - TN in Content and Language Integrated Learning (CLIL), AP in Literacy Studies, SS in Professional Discourse Studies - which are not necessarily considered to be core areas of AL. The idea here is to reflect on these domains from our individual experiential perspectives while trying to find connections as far as practising AL is concerned.

SS: The character and scope of AL receive topical attention at regular intervals in relevant journals and conferences and also in book format, including Handbooks (Candlin and Sarangi 2004a). Many discussions begin with Pit Corder's seminal work Introducing Applied Linguistics, which characterises AL as an activity:

The application of linguistic knowledge to some object - or applied linguistics, as its name implies - is an activity. It is not a theoretical study. It makes use of the findings of theoretical studies. The applied linguist is a consumer, or user, not a producer, of theories. (Corder 1973: 10)

This is echoed by Halliday (in Halliday and Burns 2006). Such a categorical definition may be seen as being straitjacketed in application (e.g. language teaching as the target object), monolithic in theory (e.g. primarily equated with linguistic knowledge) and circumscribed as far as the role/identity of the applied linguist is concerned (as consumer/user of theory). However, such a definition might be in tune with the times - historically speaking - when AL was emerging as a distinct disciplinary activity. In subsequent years, many applied linguists have distanced themselves from Corder's categorically narrow definition, as suggested by Widdowson's (2000) juxtaposition of 'linguistics applied' (corpus analysis and critical discourse analysis as exemplars) and 'applied linguistics' 
in an attempt to broaden the scope and status under the latter label, as a way of highlighting applied linguists' active, mediating role in relation to theories and principles derived from linguistics and other disciplines as well as from contextually embedded practices. For Widdowson, the underlying uncertainty, bordering on elusiveness, about AL's scope and status sustains applied linguistic activities.

This broadening of the scope is captured in Christopher Brumfit's (1995: 27) often-cited definition of AL:

The theoretical and empirical investigation of real-world problems in which language is a central issue.

This acknowledges the interface between theory and evidence-based practice, which amounts to an expansion of the object of AL to engage with language-centric real-world problems. At the same time, it leaves open how one determines which of the real-world problems are centred on language. Widdowson (1996: 125) offers a more cautious formulation, whereby dealing with 'everyday problems in which language is implicated', even if it does not take centre stage, is worth pursuing. (See the editorial by Cook and Kasper [2005] in the journal Applied Linguistics and the contributions to the special issue titled 'Applied Linguistics and Real-world Problems'.)

In line with Widdowson's formulation, we can ask: Aren't real-world problems like climate crisis, public health risk, human rights violations, warfare and the refugee situation underpinned by language and something else? Additionally, who is ratified to identify and define what constitutes a problem? Should it be the self-styled applied linguists themselves, or the practitioners and the research subjects? Or, should the problem-definition be undertaken in joint collaboration?

In a (Kenneth) Burkean sense (Burke 1966), applied linguists with either a linguistics disciplinary background or a domain-specific professional background (e.g. language education, language acquisition, language assessment, language policy) are very likely to define a real-world problem from their own perspective from among many competing alternatives. Although Burke does not include a linguist's or applied linguist's perspective in relation to what he labels the 'terministic screen', it can easily be deduced from the quote below:

Any definition of man in terms of specialised scientific nomenclatures would necessarily be 'over-socialized,' or 'over-biologized,' or 'over-psychologized,' or 'over-physicized', or 'over-poeticized,' and so on, depending upon which specialized terministic screen was being stretched to cover not just its own special field but a more comprehensive area. (Burke 1966: 52)

This acknowledges the inevitable bias - 'over-interpretation' - in any disciplinarily motivated engagement with real-world phenomena. The JYU profiling 
initiative in applied language studies, RECLAS, embodies a societal change perspective, with language taking centre stage, so a brief overview of the RECLAS agenda is in order.

TN \& AP: Let us start by contextualising the RECLAS initiative from an institutional perspective. As already pointed out, it is the result of a new strategy-based competitive funding from the Academy of Finland, the major research funding organisation in the country, for Finnish universities to strengthen their core fields and research profiles. Based both on JYU's long specialisation in AL (for a more detailed discussion, see Kalaja et al. 2013: 170-171) and long-term strategic work around languages and language education, shown for example in the establishment of professorships in key areas of research (language learning and teaching, discourse studies, language assessment, language education policies), Applied Language Studies for the Changing Society was suggested as one of the profiling areas and funding was awarded for 2016-2020.

In this institutional setting, and with the aim of strengthening the foothold of language studies and AL in the university structure, an agenda of inclusion was a logical starting point. In other words, we wanted to include and make visible the large critical mass housed in different units working on language-related matters in JYU, which spanned research expertise from language learning and teaching in first, second and foreign languages, to language assessment, discourse studies, sociolinguistics and language and education policies. As a legacy to the so-called Language Campus collaboration across different units in JYU, we drew upon our earlier experience of bringing these areas together, e.g. in our local and international events and in funding applications. From the start, we wished to include language researchers as broadly as possible within the three thematic areas included in the application - language learning and assessment, discourse studies and language and education policies - that reflected the institutional restructuring of different departments and units around this time.

To do justice to this broad set of expertise, we opted for the formulation 'applied language studies' rather than 'applied linguistics' in naming the profiling area. In other words, without consciously orienting to Corder's or Brumfit's definitions, it is clear that our approach came closer to Brumfit's idea of combining theoretical and empirical perspectives. This was expressed in the application as follows:

To describe the research field we use the notion applied language studies instead of the more typical disciplinary term applied linguistics to emphasize our aim to resignify the theoretical and methodological foundations of applied linguistics. 
In institutional terms, then, the motivation for the term 'applied language studies' was inclusive, seen as broad enough to capture most of our research. At the same time, it served as characterising the JYU profile in international comparison.

It can be argued that the inclusion agenda also led to the broad framing of the venture on issues of language 'for the changing society'. This broad framing made it possible to include all the areas described above, albeit also leaving a certain degree of vagueness and openness. It can also be argued that bringing together language and society in the title aligns with Brumfit's idea of AL as tackling real-life problems with a change agenda. It also foregrounds the language-related changes underpinning contemporary societies, with particular reference to Finland, as a key area of interest for AL. In the application, this was framed as follows:

Applied language studies can help address language-related cultural, social and economic changes that continue to exert their influence in Finnish society, its use of languages and its language needs.

Consequently, such changes in society may also have implications for the field of AL by calling for its theoretical and methodological redefinitions.

In hindsight, then, an inclusion agenda can be identified even if these considerations did not explicitly guide the proposal writing. However, it is also worth pointing out that both of us were department heads at the time. That institutional role offered us a view to the entity of research activities carried out in the two units (Centre for Applied Language Studies; Department of Language and Communication Studies) and it also motivated us to encompass rather than narrow down the coverage in the interest of supporting and strengthening the whole research area within the university.

SS: Let me turn to the ambivalence inherent in the label 'RECLAS.' 'Change' in relation to 'language' appears as key to AL activity/practice. It does imply a broader view of language (language studies) rather than what strictly falls under linguistics, but the ambivalence I am pointing to concerns whether language-centred research in Brumfit's sense can lead to changing practices in a given society or whether it involves the observation and documentation of the ever-changing society, including changes at the level of language use. A corollary of the latter would be the lexicographer's task in announcing the 'word of the year' in the context of the Oxford English Dictionary in terms of coinage/usage reflecting societal change.

There are two preliminary remarks to be made in understanding the motivations and ambitions of RECLAS in relation to Brumfit's definition: he men- 
tions a 'problem-orientation' but does not use the word 'change', whereas the RECLAS label foregrounds 'change' but does not explicitly mention 'problemorientation'. However, a problem-orientation per se cannot be justified without a change agenda. Likewise, no motivation for change can be legitimised without a problem-orientation. So, the linkage between real-world problemorientation and change in practice can be seen as integral to the interventionist agenda of applied linguistic endeavour.

Let us dwell a bit on whether problem-solution rather than problematisation of real-world phenomena (e.g. climate crisis; pandemic outbreak; warfare) constituting the core agenda of $\mathrm{AL}$ is worth commenting upon. Looking at it from Brumfit's definition, we can say that in the cases of climate crisis, pandemic outbreak and warfare, language is implicated (e.g. in how information is coded and communicated via different media and public relation offices as well as negotiated by different audiences), but despite its constitutive dimension language may not have a central role in problem-solution. In this respect the language repertoire surrounding a crisis can be a legitimate subject matter for corpus linguistics and rhetoric/discourse analysis (cf. the field of crisis communication), but not for AL, because it is not change-driven at the language level despite its real-worldly character. For instance, representations of the climate crisis (e.g. lexical upgrading of climate change to climate crisis) and the coronavirus (epidemic to pandemic) can be documented and analysed qualitatively (lexically/discoursally/rhetorically) and/or quantitatively (corpus linguistics), but it is unlikely that linguists or applied linguists of any denomination would be invited to the decision-making table or be seen as relevant to publicly comment on attendant language practices surrounding change underpinning such real-world phenomena.

A revisiting of Brumfit's definition suggests that it is the applied linguist who identifies/nominates what counts as real-world problems where language plays a central role. In this formulation of the problem, a reciprocal perspective is silent, i.e. that the problem is identified by someone other than the applied linguist. This may bear upon Crystal's self-characterisation as a 'jobbing linguist' - defined by Brumfit as 'someone who offers technical skills in the service of somebody else's activity' (in Brumfit and Crystal 2004: 390). For Crystal, this amounts to the applied linguist being always in a responsive mode to problem solving instead of being a 'straight linguist': 'because people would come up with language problems and ask for help, and you just have to respond. [...] I've always had a problem solving conception of applied linguistics' (in Brumfit and Crystal 2004: 384). Crystal's problem-solving conception of AL can be juxtaposed to Brumfit's proactive positioning in relation to problems, given Brumfit's broad educational orientation, i.e. how to address potential problems in an anticipatory manner. 
TN \& AP: There are two issues raised above: regarding real-world crises and whether these are language-centric; and the overarching dialectics between problem orientation and change. In relation to the first, the AL community needs to articulate more strongly its language-as-communication and multiliteracy perspectives, that its view of language encompasses the real-life functions and consequences of language use. From this integrated perspective, and using the current pandemic situation as an example, AL could potentially claim relevance at the level of decision making as regards navigating the mix of information and disinformation around the topic and offering pointers towards critical information literacy.

Concerning the second issue, and returning to the context of RECLAS, we can reflect on how the problem-orientation vis-à-vis change developed in our research community. One of the first things to discuss when starting to plan activities in the profiling area was how to designate ourselves. The name of the profiling area was Applied Language Studies for the Changing Society, but how do we go about labelling the research community? The number of researchers working in the broad area of applied language studies was considerable, and we wished to bring people working in different areas of language studies together; at the same time, we anticipated that this would not be an easy task. We felt therefore that the name of the profiling area should reflect both the openness of the community and the low-threshold non-hierarchical nature of our ways of working. For these reasons, the steering group suggested a change in the name to the larger research community and a decision was made to adopt the name Research Collegium for Language in Changing Society, RECLAS for short. What is notable here is that the new name highlighted language more than the earlier name Applied Language Studies for the Changing Society. In a nutshell, introspectively, we were dealing with a problem of group identity and were amenable to change.

As pointed out above, in the application phase, RECLAS embraced three thematic areas (language education, learning and assessment; discourses of mobility, diversity and language; policies, assessment and the social structure), although the aim was to move beyond and across these areas. The leaders of the three thematic areas decided that our focus would primarily be on language and on change, and that we would try to unpack these concepts in various kinds of seminars, publications and so on. The idea was that this primary focus would link the areas and possibly create new ones (not in addition, but instead of them); i.e., create integration between the designated areas. 
The three designated areas started by working fairly independently at first. They organised different kinds of seminars around the themes of the focus areas and around language and change. However, it very soon became evident that several of the topics discussed within the thematic areas overlapped and crossed the thematic boundaries. This may have been partly because we all more-or-less shared an understanding of language as a social, contextual and multimodal phenomenon and therefore similar issues were cropping up in discussions irrespective of the thematic areas.

Despite the thematic areas having shared concerns, we also noticed that organising work around them started to have a silo effect despite the original idea of moving beyond them with commonality of interest. Therefore, we gradually started to move away from them as a structural frame towards forms of activities. What we had seen was that the development of a research field, which was the aim of the profiling exercise, could not be reached either through unrestricted inclusion or through organising work around thematic areas. As it seemed to be impossible to create coherence within the thematic areas and across them, let alone in the broader field of AL/applied language studies, we decided to focus more on developing the research environment (not the discipline as such) and on creating opportunities for researchers to develop their work in new ways. We incentivised people into new directions (also discipline-wise) by offering small-scale funding, especially for new openings in research that would cut across the thematic areas, and in this way subtly guided research activities into certain directions. Thus, ultimately, our take on change meant preparing researchers for change by creating spaces and opportunities for self-change. The idea was that promoting readiness for change in general may lead to change in the research field.

SS: Of the previous JAL conversations I mentioned at the outset, the piece between David Crystal and Chris Brumfit (Brumfit and Crystal 2004) explicitly addresses the notion of change in AL. So, let me, selectively, refer to the BrumfitCrystal conversation as we move along. Crystal remarks: 'It is impossible to delimit the area of applied linguistics because society keeps changing, and new types of problems keep coming up to which linguistics can make a problemsolving contribution' (Brumfit and Crystal 2004: 385). He later underscores that old conceptions of language simply cannot explain the reality out there.

TN \& AP: From the RECLAS viewpoint, what has been embedded in our activities all along is the need to expand the notion of 'language' to make sense of its role in the changing society. As our research embraces studies 
on first, second, foreign, heritage, oral and signed languages, the concept of 'language' is naturally stretching the boundaries of conventional definitions. The basis for conceptualising 'language' arises from the multimodal totality of the communicative resources that people have at their disposal and from the fact that 'language' is acquired and learned and that it develops in different spaces throughout the life span. This is one aspect of attending to change, in that the emergence of new and changing technologies and platforms, for example, tends to mean also that the notion of language needs to change.

SS: It is worth noting that Brumfit (in Brumfit and Crystal 2004) prefers 'language practices' to 'language. We can extend this to literacy practices, including multimodality. The concept of 'literacy' might better capture the multitude of meanings that the concept of language carries today. Metaphorically speaking, more real-world problems might be caught in the literacy/multiliteracies net than in the language net, as is evident in information/disinformation practices surrounding the COVID-19 pandemic. From the viewpoint of AL, it also means embracing multidisciplinary perspectives, and this raises a question: How does this affect AL as a field? Is it the case that there is a specifically AL disciplinary perspective to real-life problems?

The stratification of $\mathrm{AL}$ as a discipline in terms of thematic areas (as in the case of scientific commissions under AILA (Association Internationale de Linguistique Appliquée) or special interest groups at the level of national AL associations (e.g. BAAL, AAAL, AFinLA) and in journals bearing the term 'applied linguistics' is less than transparent. Quite rightly, Seidlhofer (2003: 270) points to the absence of 'any unifying principles or defining criteria for what is to be included in AL'. According to her, instead of defining AL in terms of scope or coverage and various topical areas of interest, we need 'more powerful procedural definitions of what Applied Linguistics attempts to do and how it attempts to do it' (Seidlhofer 2003: 271). Despite this call for a redefinition of AL on procedural lines, the controversies she lists are issue-driven: linguistic imperialism / English as a Global Language / World Englishes; corpus linguistics and language teaching; second language acquisition; the positioning of critical discourse analysis with regard to analysis and interpretation. Shouldn't we take 'procedural' to mean 'practices' underpinning AL, and more importantly, applied linguists - i.e., how we practise applied linguistics?

This shift in orientation in our definitional task is more useful than the task of listing content areas in the spirit of inclusiveness. Indeed, the everexpanding list of content areas runs the risk of not only making AL look more dispersed, but also potentially of distracting us from a kind of unifying practice orientation. Two things come to mind. First, in thinking of procedures 
and practices, we need to attend to applied linguists as agents of practice, as practitioners committed to following ratified sets of procedures. Although it would be naïve to regard all applied linguists as belonging to a coherent 'community of practice' (Lave and Wenger 1991), the lowest denominator must be that all applied linguists do uphold a 'community of interests' (Sarangi 2015).

Second, we also need to distinguish between AL and what non-applied-linguists' practices and procedures are. Any definition of phenomena - conceptually or procedurally - is better appreciated with a juxtaposition or negative definition: what something is not. Corder's (1973) definition of AL, although delimiting, does include a negative definition - that applied linguistics is 'not a theoretical study'.

TN \& AP: In RECLAS, as a microcosm of AL, this problem of dispersion was visible in two ways. The already diverse content areas covered became even more diverse through engagement with incoming visitors and members of the Scientific Expert Group (SEG) that, only naturally, often meant the addition of their specific research topics to RECLAS. This inevitably led to the re-emergence of silos that the inclusive agenda had sought to avoid, with community members, in the face of a multitude of content areas, tending to attend and join events dedicated to topic areas corresponding to their research interests (e.g. language learning, social media, politics of education). This led to us directing added emphasis on capacity building and arranging events tied to cross-cutting concerns such as research ethics, methodological principles and publication processes as a way to counterbalance thematic dispersal and to make RECLAS relevant for researchers across different topic areas. We saw the theory-practice interface as latent in all our activities.

SS: This revamped suite of activities focusing on ethics, methodology and dissemination relates to a further remark by Crystal (in Brumfit and Crystal 2004) about the sense of readiness for emergent problems at a contingency level. In other words, real-world problems defy calculative anticipation. Ethical and methodological preparedness makes one ready with a skill-set that is transferrable across themes and contexts. Also, readiness for alternative modes of production and dissemination of research-based knowledge will serve similar purposes. The readiness also means a willingness to collaborate across disciplinary boundaries and in conjunction with research participants and practitioners. We have to acknowledge that inter-/multi-disciplinary work is always tricky. In the name of crossing boundaries - similar to migration we observe the phenomenon of budding applied linguists 'flying out' to other disciplinary corners with little intention of flying back in. 
TN: It will be useful to shed some light on who takes the initiative for such collaboration across disciplinary boundaries and what role is accorded to the AL agenda in such cases. We have noted the 'flying out' phenomenon in AL researchers - for example, adopting concepts, ideas and processes of social sciences - but there are fewer examples of non-applied-linguistics researchers 'flying in', i.e. other research areas recognising the value of AL perspectives. What does this tell us about the nature and future prospects of the field?

SS: The similarity between RECLAS and AL is striking: both can be seen as spaces for nurturing, making researchers ready for doing a host of other things, yet often without a sense of attachment and ownership. One-way migration, if it serves the core purpose of real-world problem solving, is to be seen as rewarding - a kind of altruism embodied in practising AL.

Returning to the material practices of applied linguists in relation to problematisation and the change agenda, it is necessary to foreground the practice of collaboration in the research process. From the outset, we can distinguish between, on the one hand, collaboration with research participants, including professional practitioners like teachers and doctors, and, on the other, collaboration with fellow researchers, especially from other disciplines under the labels of interdisciplinarity and transdisciplinarity. While the former is premised on the notion that participants'/practitioners' insights can enhance our understanding of the problem being investigated, the latter is premised on the fact that no real-world problem comes packaged as a disciplinary problem. More specifically, applied linguists are likely to see language-related implications of the so-called 'real life' problems, thus necessitating collaboration among other discipline-based experts. This will amount to minimising, if not overcoming entirely, the Burkean 'terministic screen', while recognising the extra-language aspects of real-world problems. A third dimension concerns collaboration with practitioner-researchers, i.e. practitioners who are researchers in their own right.

This relates to the much discussed 'research on, for, with' paradigms (Cameron et al. 1992). On the surface, 'research for' and 'research with' would fit the applied linguistic collaborative practice, but a precondition for conducting 'for and with' research is the credibility of the AL researcher, i.e., why they, rather than psychologists, sociologists, educationists, cognitive scientists etc., should offer themselves or be chosen as the ones to collaborate with. Who initiates the collaboration and what might be at stake are not inconsequential. Rather than calibrating the nuances underpinning the prepositions - on, for, with - the term 'research' needs to be broken down into its essential parts and procedures vis-à-vis collaboration: framing of the research question (joint problematisation), deciding on relevant data and methodology (shared decision making), collaborative interpretation of data and findings, and commu- 
nicating findings collaboratively (see Roberts 2003, especially her suggestion to add an 'act with' dimension to 'research with' [p. 136]). It is quite rare to see collaboration across the research process in the field of AL.

TN: To pick up on this point, matters of collaboration play a role in AL already when choosing, for example, methods such as participatory ethnography or action research. It will also be interesting to see whether the currently growing interest in citizen science, also within social sciences (Heiss and Matthes 2017), will contribute to AL in the future. Citizens' participation in all stages of the research process is seen as a key feature of citizen science and, if adopted in AL, would further contribute to the need to reconsider the role of research collaboration.

SS: From my own experience in the field of healthcare communication (Sarangi 2002, 2005), I admit that collaborative research may occasion interpretive tensions that require careful orchestration. I characterise this scenario as 'experts on experts', where reciprocal calibration of epistemologies is a necessary condition for sustainable collaboration and potential uptake (Sarangi 2015). The interpretive burden cuts both ways: for the language/communication researcher to make sense of professional expertise/practice; and for the professional practitioner to make sense of the language/communication researcher's interpretive repertoire or metalanguage - thus affecting uptake/ impact of knowledge generated through the research process.

TN: I have experienced conflicts when discussing the role of language in Content and Language Integrated Learning (CLIL) with a researcher viewpoint of language as an enabler and a necessity in meaning making - this has been confronted with teachers' view that attention to language would entail focus to details of grammar and vocabulary that content teachers see as outside their remit, hence the belief 'I'm not a language teacher'. In such cases, collaboration cannot mean researchers imposing their views on practitioners, but there has to be a mutual sense of learning from each other (cf. praxis-idea - Lantolf and Poehner 2014). From an AL researcher viewpoint, this would mean being open to teachers' views of what helps and hinders learning, to how (and whether) they see language playing a role in this and to engaging with them in joint reflection on whether research-driven and practice-driven insights on language can be intertwined to support learning.

The question of ethics also comes into play: when engaging in AL, what practitioners see as key issues may not align with language-related problems, and they may be reluctant to reflect on or problematise their practices along those lines. Is it ethical, then, to pursue language-related views in the sense of 'awareness raising'? For whose agenda is that important? 
AP: Literacy research in educational contexts bears many of the similar challenges of collaboration with practitioners as any research in educational settings might include. In my own research, the collaborators are most often either teachers or learners in schools or other institutional settings. Entering schools as a researcher is a challenge overall and recruiting collaborators is a long process, as mostly there appears to be reluctance to open one's classroom to research. There are several potential reasons for this reluctance. The question of evaluation or judgement is always present in school settings, which is at least partly due to media discussion, in which the school is constantly under the public eye. Demands on the teaching profession are constantly changing, as the education of citizens for the needs of society keep changing. The same fear of evaluation and/or judgement concerns learners in the classroom. It is perhaps even more likely that learners now feel that their performance is being evaluated, as assessment is such an inherent part of school cultures.

These underlying fears of being evaluated inevitably lead the teacher or the learner to think that there is something wrong or lacking in teaching practices or in learners' performance, and that the researcher aims to enter the field 'to fix a problem' or 'to change practices. Overcoming this deficiency discourse, which has characterised the discussion concerning literacy development as well (literate vs. illiterate), takes some effort on the part of the researcher. The researcher needs to convince the teachers and the learners that the interest of the study lies in understanding what is going on in the classroom and not on advising, and that the observer wishes to learn from the practitioners, who are indeed the experts of the processes and practices in the classroom.

SS: I think we are variously touching upon what may be called 'the ethics of researcher positioning in collaborative research' In the CLIL setting, it may be a challenge to underplay the AL researcher's language specialisation. In the context of literacy research in educational settings, the researcher may not be perceived as a neutral observer but as a potential assessor of teachers' and learners' performances. Irrespective of the goodwill, and because of the initiative shown by the researcher, this may come across as 'research on' rather than 'research for' or 'research with'. The ethics of collaboration are not that straightforward.

The theme of collaboration - or rather, division of labour - is implicit in Crystal's observation that in the past linguists and applied linguists 'didn't respect the range of non-linguistic factors that underlay the problem they were asked to help solve' (in Brumfit and Crystal 2004: 385). I would interpret Crystal's position to mean that there is more to a problem than meets the 'lin- 
guistic eye', and, by extension, many of the problems encountered by applied linguists cannot necessarily be solved by linguistic knowledge/scholarship.

Crystal's remark points to the limitations of linguistic expertise, and raises questions about Brumfit's definition which foregrounds 'real-world problems in which language is a central issue.' Brumfit's position seems to suggest there are language-centred problems which can be separated from the rest (nonlanguage problems). For Crystal, every problem is a compound made up of language and non-language components that are inseparable. So, if we only focused on the language part of the problem, then our investigation and findings would be partial, a 'metaphorical pretence.' To quote Brumfit (in Brumfit and Crystal 2004: 397), 'all studies of social phenomena have on the one hand a concern to idealise, which is essentially a metaphorical pretence that you can isolate the phenomenon that you're looking at, and on the other the need to be embedded in real-world practice'.

For Crystal, the terministic screen can be overcome through respecting 'the non-linguistic factors that underlie problems'. By extension, this can mean joined-up investigation of problems through a collaboration between linguists and non-linguists. This remains implicit in Crystal's remarks; however, he is silent about the collaborative involvement of the research participants with regard to problematisation and problem-solution.

TN \& AP: In the RECLAS community, such collaborative involvement of research participants and reaching out to non-linguists can be seen especially in participatory and ethnographic research. These kinds of projects have engaged in extensive fieldwork with e.g. lawyers, migrant learners, asylum seekers and multicultural communities, including joint problematisation and problem-solution. This take on research reflects our shared broad understanding of language as communication and literacies, and highlights the nature of AL research as socially relevant.

SS: Social relevance as well as the problem-solution orientation of AL cannot always be taken for granted. In recognising the complex nature of real-world problems, Crystal points to a dilemma concerning the trading relationship between linguistics and applied linguistics which is at the same time both enervating and frustrating. As he puts it: 'do you go back and become a linguist again in order to help solve the problem, or do you stay an applied linguist and ask for an easier problem to solve?' (in Brumfit and Crystal 2004: 391). This is an intriguing proposition, which aligns with the tradition of social construction of problems: i.e., generally, experts formulate problems according to their expertise in solving such problems, whereby selectivity and bias are unavoidable. It reminds me of the proverbial 'law of the hammer': 'It is tempting, if 
the only tool you have is a hammer, to treat everything as if it were a nail' (Maslow 1966: 15). Maslow's 'law of the hammer' (based on Kaplan's [1964] 'law of the instrument') represents narrow-minded instrumentalism, or overreliance on a familiar tool, which is characteristic of much scientific inquiry. Basil Bernstein's (1975: 160) observation in relation to sociology of education research is salutary: what is required is 'less an allegiance to an approach, and more dedication to the problem.

The dilemma applied linguists in the university sector face is a real one: while trying to remain focused on practical problems they have to comply with their institutionally mandated reward system, which prioritises a form of instrumentalism qua scholarly outputs in high-esteem journals and books. In the context of applied linguistic research practice, and with specific reference to Chris Candlin and his colleagues' pioneering work in the 1970s, Greg Myers (2018: 227-228) comments:

I would argue that it shows how change results from the interaction of highly specific, practical demands for application, in a specific setting and within a specific timeframe, with broader theoretical and methodological frames that enable the researchers/course developers to see what is missed or taken for granted in the practices. We misunderstand an applied field if we focus on the development of new concepts and approaches ('the communicative approach', 'Critical Discourse Analysis', 'superdiversity'), or the importation of concepts from other disciplines, as if they were the result of an autonomous academic process. We must also consider the institutional context and social demands that make such developments possible (such as diverse funding sources) and the ways academics and non-academics engage with each other (for instance, in long-term informal networks) [...]. The challenge for an applied field, which is always drawn further into the academic discipline and its reward systems, is to keep returning to the practical problems and to adapt the research tools to them, instead of just making those problems fit whatever tools are currently in favour.

Here we have the issue of 'importation of concepts from other disciplines' being seen as trendy (for a discussion of influences in (inter)disciplinary practice, see Cicourel and Sarangi 2018), which carries academic rewards but can potentially distance oneself from engaging in a sustainable way with the practical problem in hand, and blur the phenomenon for the practitioners. Sustained collaboration between 'academics' and 'non-academics' has to be seen as the crux of an applied field.

TN \& AP: This blurring of the phenomenon becomes particularly salient when talking about 'language'. For example, in research on language education, researchers may wish to adhere to concepts such as language repertoires or language as resource to recognise and value multilingual practices. Yet the educational system is built upon named languages, and 
thus finding a common language with practitioners to address the issue requires constant negotiation.

SS: Collaboration with professional practitioners is fraught with tensions. I can easily relate to Crystal's metaphorical remark: 'One of the most important attributes of applied linguists is that they should have thick skins' (in Brumfit and Crystal 2004: 393). He recounts his compromising stance with speech therapists concerning categorisation of practitioners' activities vis-à-vis the established clinical linguistics profile: 'The linguistics side has to accept a certain amount of simplification of the descriptive statements that have to be made and the speech therapy side has got to be prepared to take on board a certain amount of unfamiliar technicality' (in Brumfit and Crystal 2004: 392) (for a similar account in the context of genetic counselling, see Sarangi et al. 2003; Sarangi 2015). When working with professional practitioners like speech therapists and genetic counsellors, one must be prepared for 'getting the stick' from both sides - the practitioners as well as fellow academics. In such a context, 'thick skin' is to be regarded a positive attribute: rather than coming across as being insensitive and indifferent, one demonstrates readiness to compromise and even willingness to retract their intervention and accept failure.

TN: Being thick-skinned then can also mean being flexible in the face of resistance that comes from practitioners' side. As an example, CLIL teachers teaching their subject through L2 may react very strongly to ideas that a more language-aware work practice might benefit their students' learning, because they reject the idea that their role would in any way be to focus on language - which, as pointed out earlier, they often interpret as focus on grammar or other accuracy matters. Therefore, what I have found a more fruitful avenue than starting from language has been to talk about different subjects having their own specific ways of meaning making / knowledge construction, and to invite teachers themselves to consider how those might be visible in language. This highlights the teachers' own professional expertise and insights, and the practitioners have been more ready to go along with such an approach and reflect on the role of language as well as the relationship between language and content.

SS: Greg Myers (2005), based on his public opinion research, is cautious about presenting ourselves as experts and underscores the fact that 'practitioners and academics may not conceptualize the "real-world" problem in the same way [...] [and they] may not conceptualize "language" in the same way either' (Myers 2005: 540). On a related note, when it concerns channels of communi- 
cation of research findings in the sphere of professional practice, a principle of mutuality must take precedence over a top-down format, to preserve integrity on both sides and ensure usefulness. I am reminded of the personal communication with Frederick Erickson in relation to a paper Celia Roberts and I were writing about uptake of discourse-analytic research findings at the time (Roberts and Sarangi 2003):

Achieving usefulness of discourse analysis for practitioners is not simply a matter of 'downloading' academic information on a passive audience of practitioners in a oneway (and top-down) process of transmission, but involves a complex process of discursive interchange - interdiscursivity - in which considerable reflective awareness is necessary by the discourse analysts themselves.

TN: I guess this also ties in with the concern that analysts may have about whether their interpretations do justice to the practitioners' lived reality. Yet I doubt if there is a possibility for full compatibility of analysts' and practitioners' views: their gazes are by definition different, and it is the very tension that has the potential to create cracks in the taken-for-granted ways of thinking for both sides.

SS: Aaron Cicourel's (1980) caution about equating participants' reasoning with analytic reasoning is worth revisiting here:

Forms of reasoning are viewed as central to the researcher's understanding of the way speakers and hearers presumably understand each other. The forms of reasoning we attribute to the participants of discourse parallel the reasoning we employ as researchers in making sense of the speech acts we record and listen to in arriving at some form of analysis. But as researchers we can, of course, specify formal aspects of discourse, produce systematic descriptions, and note emergent properties of the interaction. Yet we cannot attribute such properties unequivocally to the knowledge base of the participants. (Cicourel 1980: 101)

If we accept that there cannot be full 'reciprocity of perspectives', then this raises the question about whether the analyst can ever embed an emic perspective or member's method. Could such claims of 'participant perspective' be a pretence, underpinned by the moral high ground? Does the 'participant perspective' become a cloak in which the analyst's interpretation will go unchallenged? Or, is it a matter of the analyst approximating the participant's perspective and not reading off the data in a top-down manner? Note that, the opposite stance, bottom-up, does not necessarily assume the participant's perspective as a starting point in the interpretive act.

An additional concern is that the members'/participants' perspectives are not a homogenous entity. In the pedagogical setting, like in the clinical setting, 
the teachers'/doctors' and students'/patients' perspectives may not align. In such instances, the researcher-analyst is expected to remain unbiased by not privileging one perspective over another, while being guided by what is manifest at the level of empirical evidence. But, interpretively speaking, taking sides is unavoidable (see Becker 1967), which in many instances is unintentional and therefore not declared as such.

TN: Could the ball here be thrown to what is seen and taught as good academic writing/reporting? How much room is there for making variability and heterogeneity visible and a worthy finding rather than aiming at 'clear' results, which may produce 'taking sides'? When reporting, should we be more open about the inevitable incompleteness of our accounts and admit that we never fully understand each other's operating environments? Yet I have also had experience of practitioners - teachers in my case - having gained insights about their practice through shared reflections on research data. For example, through 'discursive exchange' and shared attention to recurrent patterns in details of classroom talk, they have started to notice how small matters that they may have paid little conscious attention to, such as their ways of formulating questions or ways of reacting to student responses, can have fundamental consequences for the atmosphere in classrooms or for pedagogical success.

AP: This reminds me of the concept of literacy practices, where practice extends beyond action and talk about the action to thinking, values and ideologies and thus fundamentally differs from many discourse analysts' understanding of practice.

SS: The metaphor of tree and wood is apposite here - missing the wood for the tree as well as missing the tree for the wood. Whatever may grab our research attention at a detailed - and by default narrow - level may not be of interest to the practitioners, and thus be seen as inconsequential. A focus on certain linguistic features in preference to others carries the distinct possibility of partial interpretation at best and over-interpretation at worst (see ethics of interpretation - Sarangi 2019).

I think 'the discursive exchange' is needed at the pre-analytical stage, in agreeing what might constitute the focal analytical interest, although it is not a simple matter to forecast such precision within the paradigm of qualitative inquiry. Nonetheless, it takes us to the core of any research activity - that there is a genuine epistemological/ontological niche to be brought out analytically/ interpretively. In this process, however minor an analytical feature might be, it could potentially offer useful insights in patterned ways. Very often identi- 
fication of such patterns coincides, intuitively, with practitioners' taken-forgranted knowledge. With their interpretive rigour, the analyst enables the process of reflexivity, and thus creates the conditions of practical relevance. Tony Hak's (2000) observation is relevant here:

Even if practitioners may agree with discourse researchers that a research focus on talk or discourse is justified - which usually is not the case - this does not mean that they will bring the same kind of concerns to the analysis. Practitioners will find it difficult or even impossible to bring other criteria to an analysis than professional standards (such as described in text books and used in audits and in supervision) and organisational concerns (such as avoidance of complaints by clients, keeping to time constraints etc.).

TN: This, again, brings to my mind that CLIL teachers (i.e. content teachers) often react very strongly to suggestions to pay more attention to matters of language, seeing this as adding extra work to their already full workload and making it more difficult to reach the curricular objectives. Articulating a different kind of understanding of 'language', one that points to the importance of meaning-making practices typical for the subject that they teach, rather than language per se, is needed.

SS: The CLIL scenario does show the cracks in the so-called 'joint problematisation' and 'joint seeing' in collaborative research. As already mentioned, I have been in many collaborative research endeavours where the outsiderresearcher, from the very outset, is viewed with suspicion by the practitioners, who, by default, become the subject/object of research. The practitioners do not always consider the outsider-researcher as 'one of us' and, worse still, the latter may be seen as a burden in terms of finding weaknesses in current practice and recommending changes, as in any educational setting. In a sense, a form of resistance is built into the collaborative enterprise - partly because of the parallel tracks the linguist-researchers and practitioners inhabit - but it does not get addressed adequately. Tony Hak (2000) further notes:

Analytic products, such as descriptions and interpretations of practitioners' actions, should always be checked against practitioners' own understandings of such actions. CA's insistence that the researcher should make only inferences about intentions, 'strategies' and meanings that are observable in the data is a useful corrective to overinterpretation on the part of the researcher. But it is rather counterproductive if it is taken as a recommendation to dismiss practitioners' accounts of their actions.

TN: I'm reacting to the word 'checked' in the above - it seems to imply that practitioners' own understandings form the yardstick against which to validate researcher interpretations. Maybe 'brought into dialogue' would work 
better, as it brings in the idea of mutual learning from each other so that in the process, both researchers' and practitioners' ways of thinking may be affected.

AP: I'm also thinking here that both perspectives might be useful and relevant, but these would have to be brought into dialogue. Sometimes researchers see something that the practitioners have not realised or have not been able to put into words, but definitely this also happens the other way round. This latter is often ignored in research projects: what and how researchers can learn from practitioners, and moreover, what could be reached by bringing the two perspectives into real and honest dialogue.

SS: I read 'be checked' as 'triangulated' - to approximate what Cicourel (2007) calls 'ecological validity' - which does not amount to giving into one particular trajectory of interpretation, or validation of analytical claims against the practitioners' yardstick. As Angus Clarke, my genetics colleague, puts it:

Interpretation of professional behaviour, and especially any attempt to evaluate professional practice, can only sensibly proceed with some input from the professionals. This is not to say that a professional's account of their practice must be taken at face value [...] but an attempt to make sense of practice without some input from professionals is unlikely to be productive. (Clarke 2005: 189)

I guess this points to a climate of mutual learning, with the provision of bidirectional 'hot feedback'. One must, however, be cautious about infinite recursivity, i.e. moving further and further away from the primary data and engaging in a continual process of mind reading. It also means that there will always be occasions of misinterpretations and contestations (Sarangi 2015). In this regard, I feel it is important that analysts routinely maintain that their interpretations are indeterminate and variable rather than being clear-cut and definitive.

In sum - and in the context of applied linguistics research - we seem to be converging on the importance of 'interpretation' of practice as evidenced in the empirical data we have access to, independent of the nature of the data and the setting - although what constitutes the focus of interpretation is subject to re-interpretation by practitioners and fellow researchers alike. It is understandable that an applied linguist will be inclined to approach the data based on their own expertise and analytical assumptions and thus run the risk of the lived reality of the practitioner simply escaping!

AP: In an ongoing project, we asked the teacher how we could help her in her work and what she would like us to focus on in the classroom. This was at first quite puzzling for the teacher, but then she got interested and started to talk about the value of having 'several pairs of eyes' in the class- 
room, as she misses a lot of what is going on in the classroom while focusing on pedagogical practices.

TN: One of the challenges in my research dealing with CLIL classroom practices has been to find ways of establishing a genuinely safe space to explore research-based observations with teachers. There are role-related tensions and asymmetries, often reflected in teachers' wishes for research to provide clearcut answers and 'recipes', when for researchers the gist lies in understanding teachers' own points of view and what is possible and what not in their everyday realities. For these reasons I don't really believe in 'impact' of AL in the sense of dramatic change in educational practices due to research. But uptake is very important - those valuable moments when researcher-practitioner engagement results in both parties learning something that may develop their thinking and ways of working. Quite often this is about creating tiny fractures in ways of thinking that may lead - over time - to bigger changes.

SS: In an attempt to conclude this conversation, let us return to 'the change agenda' which appears in our title. Highlighting the relationship between the world 'out there' and the world made manifest through applied linguistic research will remain complex and therefore the change agenda will pose a constant challenge. We may, however, begin to make a list of what needs to change. First and foremost, our conception of language has to be broadened. In terms of research methodology, there is a need to move away from an 'outside-in' to an 'inside-out' approach, e.g. building on practitioners' lived experiences and their expertise. At the dissemination stage, we need to be extra careful in how we articulate our research findings without alienating those whose practices we investigate.

However, we must realise that the research outputs thus obtained do not necessarily guarantee change in practitioners' conduct (outcomes), either immediately or long-term in a sustained manner. What may have been discovered through our research lens can still not pass the test of usefulness as far as practitioners and, more widely, societal changes are concerned. Paradoxically, outside the sphere of applied research there is the possibility of gaining useful insights via consultancy without much systemic methodology/analysis-driven discovery. How do applied linguists steer a path between research-led discovery and practical usefulness (see Rampton [1997] and the contributions to the Special Issue of International Journal of Applied Linguistics)? At such an intersection lies the task of popularisation of applied linguistics.

The change agenda may require a shift from solving real-world problems to ways of thinking about language-related problems as equally valid research outcomes. Guy Cook (2012) rightly questions whether impact is necessarily a 
measure of good 'applied' research. He historically documents how influence/ change can come about via 'commercially and/or politically viable versions of ideas' (Cook 2012: 30) rather than by 'engaging with real-world issues through reasoned argument supported by evidence' (Cook 2012: 29). The trajectories of research are often long and painfully slow, and where there is credible research evidence, the changes may happen at the micro-level rather than on larger issues such as language planning, language education at governmental policy level, especially if research findings do not fit existing practices and ideologies (see the discussion in McIntyre and Price 2018).

A genuine question remains: in what ways can journals like JALPP embrace change? In the past I have experimented with different article formats, with very little success. Over the years the rift seems to widen between the societal contingencies we wish to engage with and change where possible, and the institutional mandates about what counts as scholarly output (including where it is published). This conversation has all the ingredients to continue into eternity without resolution!

\section{About the authors}

Srikant Sarangi is Professor in Humanities and Medicine and Director of the Danish Institute of Humanities and Medicine (DIHM) at Aalborg University, Denmark. $\mathrm{He}$ is also Emeritus Professor at Cardiff University; Adjunct Professor at NTNU (Norway); and between 2017 and 2020, Visiting Professor at University of Jyväskylä (Finland). In 2012, he was awarded the title of 'Fellow' by the Academy of Social Sciences, UK. His research interests are in institutional/professional discourse studies and applied linguistics. He is author and editor of 12 books, guest-editor of 10 journal special issues and has published nearly 250 journal articles and book chapters. He is editor of Journal of Applied Linguistics and Professional Practice, Text \& Talk and Communication \& Medicine. Address for correspondence: Department of Communication \& Psychology, Aalborg University, Rendsburggade 14, 9000 Aalborg, Denmark. Email: sarangi@hum.aau.dk

Tarja Nikula is Professor of Applied Language Studies at the University of Jyväskylä, Finland. She was director of RECLAS - Research Collegium for Language in Changing Society - between 2016 and 2020. Her research interests include integrated content and language learning (CLIL), disciplinary literacies, multilingual education and the interplay between language education policies and practices. She has co-edited Conceptualizing Integration in CLIL and Multilingual Education (2016, Multilingual Matters) and Language Use and Language Learning in CLIL Classrooms (2010, John Benjamins). Address for correspondence: Centre for Applied Language Studies, University of Jyväskylä, PO Box 35, 40014 University of Jyväskylä, Finland. Email: tarja.nikula@jyu.fi 
Anne Pitkänen-Huhta is Professor of English (language learning and teaching) at the University of Jyväskylä, Finland. She is also the Vice Dean of the Faculty of Humanities and Social Sciences. Her research focuses on (foreign) language learning and teaching practices, on multilingual language education and on multiliteracies. Her research employs ethnographic, discourse analytic and visual methods. She has co-edited Literacy Practices in Transition: Perspectives from the Nordic Countries (2012, Multilingual Matters), Reconceptualizing Connections between Language, Literacy and Learning (2019, Springer) and a double special issue in Applied Linguistics Review, on 'Visual Methods in Applied Language Studies' (2018). Address for correspondence: Department of Language and Communication Studies, University of Jyväskylä, PO Box 35, 40014 University of Jyväskylä, Finland. Email: anne.pitkanen-huhta@jyu.fi

\section{References}

Becker, Howard S. (1967) Whose side are we on? Social Problems 14 (3): 239-248. https:// doi.org/10.2307/799147

Bernstein, Basil (1975) Class, Codes and Control, Volume 3: Towards a Theory of Educational Transmissions. London: Routledge and Kegan Paul.

Brumfit, Christopher (1995) Teacher professionalism and research. In Guy Cook and Barbara Seidlhofer (eds) Principle and Practice in Applied Linguistics, 27-41. Oxford: Oxford University Press.

Brumfit, Christopher and David Crystal (2004) Coping with change in applied linguistics. Journal of Applied Linguistics 1 (3): 387-398. https://doi.org/10.1558/japl.2004.1.3.383

Burke, Kenneth (1966) Language as Symbolic Action: Essays on Life, Literature and Method. Berkeley: California University Press. https://doi.org/10.1525/9780520340664

Cameron, Deborah, Elizabeth Frazer, Penelope Harvey, M. B. H. Rampton and Kay Richardson (1992) Researching Language: Issues of Power and Method. London: Routledge.

Candlin, Christopher N. and Srikant Sarangi (2004a) Making applied linguistics matter. Journal of Applied Linguistics 1 (1): 1-8. https://doi.org/10.1558/japl.v1i1.1

Candlin, Christopher N. and Srikant Sarangi (2004b) Making inter-relationality matter in applied linguistics. Journal of Applied Linguistics 1 (3): 225-228. https://doi.org/10.1558/ japl.2004.1.3.225

Cicourel, Aaron V. (1980) Three models of discourse analysis: The role of social structure. Discourse Processes 3 (2): 101-132. https://doi.org/10.1080/01638538009544482

Cicourel, Aaron V. (2007) A personal retrospective view of ecological validity. Text \& Talk 27 (5-6): 735-752. https://doi.org/10.1515/TEXT.2007.033

Cicourel, Aaron V. and Srikant Sarangi (2018) Intended and unintended influences in the shaping of (inter)disciplinary practice: A conversation between Aaron Cicourel and Srikant Sarangi. Journal of Applied Linguistics and Professional Practice 13 (1-3): 417434. https://doi.org/10.1558/japl.37506 
Clarke, Angus (2005) Commentary 1: Professional theories and institutional interaction. Communication \& Medicine 2 (2): 189-191. https://doi.org/10.1515/come.2005.2.2.189

Cook, Guy (2012) British applied linguistics: Impacts of and impact on. Applied Linguistics Review 3 (1): 25-45. https://doi.org/10.1515/applirev-2012-0002

Cook, Guy and Gabriele Kasper (2005) Editorial. Applied Linguistics 26 (4): 479-481. https://doi.org/10.1093/applin/ami033

Corder, Pit S. (1973) Introducing Applied Linguistics. Harmondsworth, UK: Penguin Books.

Hak, Tony (2000) Professional vision and the methodology of interdisciplinary research. Paper presented at the Sociolinguistics Symposium 13: The Interface between Linguistics and Social Theory. University of the West of England, Bristol, 27-29 April.

Halliday, Michael A. K. and Anne Burns (2006) Applied linguistics: Thematic pursuits or disciplinary moorings? A conversation between Michael Halliday and Anne Burns. Journal of Applied Linguistics 3 (1): 113-128. https://doi.org/10.1558/japl.v3i1.113

Heath, Shirley B. and Claire Kramsch (2004) Individuals, institutions and the uses of literacy: Shirley Brice Heath and Claire Kramsch in conversation. Journal of Applied Linguistics 1 (1): 75-91. https://doi.org/10.1558/japl.v1i1.75

Heiss, Raffael and Jörg Matthes (2017) Citizen science in the social sciences: A call for more evidence. GAIA - Ecological Perspectives for Science and Society 26 (1): 22-26. https://doi. org/10.14512/gaia.26.1.7

Kalaja, Paula, Hannele Dufva, Katja Mäntylä and Anne Pitkänen-Huhta (2013) AFinLA: The Finnish Association of Applied Linguistics. European Journal of Applied Linguistics 1 (1): 162-173. https://doi.org/10.1515/eujal-2013-0008

Kaplan, Abraham (1964) The Conduct of Inquiry: Methodology for Behavioral Science. San Francisco: Chandler Publishing.

Lantolf, James P. and Mathew E. Poehner (2014) Sociocultural Theory and the Pedagogical Imperative in L2 Education: Vygotskian Praxis and the Research/Practice Divide. London: Routledge. https://doi.org/10.4324/9780203813850

Lave, Jean and Etienne Wenger (1991) Situated Learning: Legitimate Peripheral Participation. Cambridge: Cambridge University Press. https://doi.org/10.1017/CBO9780511815355

Maslow, Abraham (1966) Psychology of Science: A Reconnaissance. London: Harper \& Row.

McIntyre, D. and H. Price (eds.) (2018) Applying Linguistics: Language and the Impact Agenda. London: Routledge. https://doi.org/10.4324/9781351055185-1

Myers, Greg (2005) Applied Linguistics and institutions of opinion. Applied Linguistics 26 (4): 527-544. https://doi.org/10.1093/applin/ami025

Myers, Greg (2018) The syllabus and the casualty ward: A 1974 study of 'Doctor-Patient Communication Skills'. Journal of Applied Linguistics and Professional Practice 13 (1-3): 211-232. https://doi.org/10.1558/japl.31858

Rampton, Ben (1997) Retuning in applied linguistics. International Journal of Applied Linguistics 7 (1): 3-25. https://doi.org/10.1111/j.1473-4192.1997.tb00101.x 
Roberts, Celia (2003) Applied linguistics applied. In Srikant Sarangi and Theo van Leeuwen (eds) Applied Linguistics and Communities of Practice, 132-149. London: Continuum.

Roberts, Celia and Srikant Sarangi (2003) Uptake of discourse research in interprofessional settings: Reporting from medical consultancy. Applied Linguistics 24 (3): 338-359. https://doi.org/10.1093/applin/24.3.338

Sarangi, Srikant (2002) Discourse practitioners as a community of interprofessional practice: Some insights from health communication research. In Christopher N. Candlin (ed.) Research and Practice in Professional Discourse, 95-135. Hong Kong: City University of Hong Kong Press.

Sarangi, Srikant (2005) The conditions and consequences of professional discourse studies. Journal of Applied Linguistics 2 (3): 371-394. https://doi.org/10.1558/japl.v2.i3.371

Sarangi, Srikant (2015) Experts on experts: sustaining communities of interest in professional discourse studies. In Maurizio Gotti, Stefania Maci and Michele Sala (eds) Insights into Medical Communication, 25-47. Bern: Peter Lang.

Sarangi, Srikant (2019) Communication research ethics and some paradoxes in qualitative inquiry. Journal of Applied Linguistics and Professional Practice 12 (1): 94-121. https:// doi.org/10.1558/jalpp.36885

Sarangi, Srikant and Christopher N. Candlin (2004) Making methodology matter. Journal of Applied Linguistics 1 (2): 101-106. https://doi.org/10.1558/japl.2004.1.2.101

Sarangi, Srikant and Christopher N. Candlin (2010) Editorial: Applied linguistics and professional practice: Mapping a future agenda. Journal of Applied Linguistics and Professional Practice 7 (1): 1-9. https://doi.org/10.1558/japl.v7i1.1

Sarangi, Srikant, Angus Clarke, Kristina Bennert and Lucy Howell (2003) Categorisation practices across professional boundaries: Some analytic insights from genetic counselling. In Srikant Sarangi and Theo van Leeuwen (eds) Applied Linguistics and Communities of Practice, 150-168. London: Continuum.

Seidlhofer, Barbara (ed.) (2003) Controversies in applied linguistics. Oxford: Oxford University Press.

Widdowson, Henry G. (1996) Reply to Fairclough: discourse and interpretation: conjectures and refutations. Language \& Literature 5 (1): 57-69. https://doi.org/10.1177/ 096394709600500106

Widdowson, Henry G. (2000) On the limitations of linguistics applied. Applied Linguistics 21 (1): 3-25. https://doi.org/10.1093/applin/21.1.3 